\title{
Analysis of the impact of central bank communications on money market indicators
}

\author{
Diana A. Petrova \\ E-mail: petrova-da@ranepa.ru
}

\section{Pavel V. Trunin}

E-mail: pt@iep.ru

Russian Presidential Academy of National Economy and Public Administration Address: 84, Prospect Vernadskogo, Moscow 119571, Russia

Abstract

Press releases on monetary policy play an important role in the communication policy of the central bank. These press releases explain key rate decisions and provide signals about the future direction of the central bank's monetary policy. Information signals can influence the expectations of financial market participants and increase the predictability and effectiveness of monetary policy. There are not enough research papers dedicated to the text analysis of the Bank of Russia press releases and the assessment of information signals. Hence, this article examines the impact of information signals about monetary policy on the money market rate, term and credit spreads. First, we estimate latent Dirichlet allocation to determine the topics of information signals. Second, we use sentiment analysis to construct signals about easing or tightening of the monetary policy. Third, the impact of signals about the future monetary policy on the money market indicators is assessed using the exponential GARCH model. Empirical research has shown that signals of future monetary policy easing are associated with lower money market rates and term spreads, and an increase in the credit spread. The result proved to be resistant to various ways of vectorizing the text of press releases. The article was prepared as a part of the state assignment research of Russian Presidential Academy of National Economy and Public Administration.
}

Key words: press release; Bank of Russia; text analysis; sentiment analysis; latent Dirichlet allocation; money market; MIACR; term spread; credit spread. 
Citation: Petrova D.A., Trunin P.V. (2021) Analysis of the impact of central bank communications on money market indicators. Business Informatics, vol. 15, no 3, pp. 24-34. DOI: 10.17323/2587-814X.2021.3.24.34

\section{Introduction}

$\mathrm{T}$ The central bank's monetary policy has undergone many changes in the past few decades. At the moment, the traditional tools used by central banks are successfully complemented by communication policy. The decisions are taken and the current economic situation and future prospects are discussed in reports on monetary policy, at press conferences, in press releases, speeches in the media. In this case, an increase in the degree of transparency of the central bank can lead to a reduction of information asymmetry among economic agents and improve the efficiency of the monetary policy under uncertainty. The emergence of new information about the current economic situation before decision-making by agents contributes to a better risk assessment, more informed decision-making and an increase in public welfare [1-5].

Signals about the future direction of monetary policy remain a widespread way to influence financial market participants, but the central bank does not directly report on the specific timing of changes in interest rate policy $[6,7]$. Financial market participants may overreact to statements by the monetary authorities, revising expectations based on all available information and introducing significant changes, which will complicate the achievement of the central bank's goals. For this reason, most central banks provide indirect signals about the future direction of monetary policy in order to maintain the credibility of conveyed information [8].

As a result, information policy has become an important tool for central banks to effectively manage expectations of economic agents [9], increase the predictability of monetary policy decisions [10] and contribute to the achievement of macroeconomic goals of the central bank [11-15].

In this regard, it is of interest to assess the impact of the Bank of Russia's communication policy on the behavior of participants in financial markets. This study analyzes the impact of information signals about the future direction of monetary policy (MP) contained in the press releases of the Bank of Russia on the money market indicators. Quantitative indicators of information signals were estimated using the latent Dirichlet allocation (LDA) model and a dictionary for determining the sentiment for the period from January 2013 to May 2020.

The article is structured as follows. Section 1 discusses the results of international and Russian studies of the influence of information signals on financial markets. Section 2 provides a methodology for assessing quantitative indicators derived from unstructured data from the Bank of Russia press release corpus. Section 3 shows the results of an econometric analysis of the impact of information signals about the future direction of monetary policy on the indicators of the Russian money market.

\section{Literature review}

There are various information sources to quantify the signals of the central bank - press releases [16], speeches and statements in the media [17], posts on social networks [18] among others. Since this type of data is unstructured, a common approach to constructing quantitative indicators is to use dictionaries of positive and negative words or machine learning techniques to determine the sentiment of the materials. In addition, topic modeling of the central 
bank's materials can also be used to assess the importance of various economic issues at certain time intervals.

In [19], a textual analysis of the FOMC statements is carried out based on LDA and dictionary methods for the US from January 1998 to December 2014 to assess the direction of monetary policy and its impact on economic and financial indicators. The results of the study indicate the importance of information signals for financial markets: in general, with the easing of monetary policy in the future, investor optimism increases. However, communication has no significant impact on the real economic variables, excluding labor market indicators.

The paper [20] analyzes the impact of the interest rate meeting minutes of the Bank of England on the futures interest rate for the period from July 1999 to March 2014. The authors found that quantitative indicators of information signals, obtained using latent Dirichlet allocation and dictionary, improve the accuracy of the 12-months-ahead interest rate prediction.

The study [21] constructs a financial stability index based on text analysis of reports on financial stability of 35 central banks, and also examines its impact on the financial performance of the banking sector during 20052015. Generally, the authors show that a financial stability index built on the basis of central bank communications can be a good indicator for predicting a banking crisis.

In [22], textual analysis of the meeting minutes of the FOMC using latent Dirichlet allocation is presented to assess their impact on the US financial markets from January 1995 to October 2019. The author concludes that the most important ${ }^{1}$ topics for the term spread were "economic growth," "prices," "market conditions," "open market operations" and "infla- tion expectations," and for the default spread "economic growth," "open market operations," "labor market" and "bank lending."

There are also works that investigate the impact on the expectations of economic agents not only of the materials of the central bank, but also news released by the central bank in the media. In such works, it is assumed that the private sector receives and processes all available information, including channels such as the media. Media interpret the materials of the central bank in their own way and publish the views of the monetary authorities. For this reason, article [23] examines which of these two sources has a greater influence on the volatility of interest rates in Canada from December 2000 to September 2008. The authors used three types of information signals from the central bank: press releases on interest rate decisions made by the Bank of Canada Board of Directors meeting, monetary policy reports and news articles containing information about decisions made by the Bank of Canada. The results showed that there is a difference between the sources of information - the central bank's press releases and news. Discussion of macroeconomic topics or key risks in press releases, as opposed to news in the media, can have a calming effect on the financial market and lead to a decrease in the volatility of futures rates.

In the Russian literature, it is also possible to single out a number of studies in the field of analysis of the Bank of Russia's information signals. Thus, study [24] revealed a significant influence of the released news about the future direction of monetary policy of the Bank of Russia on the money market rate and the USD/RUB exchange rate for the period from April 2013 to September 2016.

In [25], a study is carried out of the influence of released news and publications of the press

\footnotetext{
${ }^{1}$ Results of evaluating the lasso model for selecting the most significant variables
} 
center of the Central Bank of the Russia on the USD/RUB exchange rate. The results of the study show that the materials of the Bank of Russia containing statements about inflationary risks and exchange rate volatility are associated with the depreciation of the USD/RUB for the period from November 2014 to December 2016 .

However, it is important to note that the studies do not examine the effect of the Bank of Russia information signals on the time structure of interest rates. This article presents the results of assessing the impact of the Bank of Russia information signals on various money market indicators. Press releases of the Bank of Russia for the period from January 2013 to May 2020 are considered as a source of information signals. Text analysis of the Bank of Russia press releases is carried out using topic modeling and the sentiment analysis based on a dictionary of positive and negative words.

\section{Text analysis of the Bank of Russia press releases}

This section describes a methodology for assessing information signals ${ }^{2}$ about the future direction of monetary policy. As noted earlier, topic modeling and dictionary-based sentiment analysis is a popular approach to derive quantitative indicators from text analysis when discussing various empirical studies on news and a central bank's press releases. In particular, researchers use the latent Dirichlet allocation [26], which has good interpretability of the received topics and the possibility of further use of the pre-trained model for clustering new documents on already defined topics. For this reason, in this work preference is given to the latent Dirichlet allocation. Next, we focus in more detail on the specification and a method for evaluating it.

We use all press releases ${ }^{3}$ of the Bank of Russia which contain information signals about the future direction of monetary policy, decisions made on credit and deposit auctions, revocation of licenses, etc.

At the stage of data preprocessing, standard procedures are applied: removal of stop words ${ }^{4}$ and rare words, lemmatization for the Russian language using the pymorphy2 package in the Python programming language. Vectorization methods are compared - a "bag of words" 5 and tf-idf .

Let us dwell in more detail on the latent Dirichlet allocation evaluated in Gensim in the Python programming language using the online variational Bayesian inference algorithm [27]. As stated earlier, it is a probabilistic model for clustering news articles or press releases on a mixture of topics. In addition, LDA provides an opportunity to calculate the probabilities of occurrence of words in a specific topic and the probabilities of each topic for a corpus of documents. The distribution of words characterizes the meaning of each topic, since the most common words in the texts related to this topic are assigned more weight. The resulting distribution of topics

\footnotetext{
2 The information signal of the Bank of Russia means information in press releases about the reasons for a possible change in monetary policy, in particular, the economic outlook and inflation risks

3 To train latent Dirichlet allocation, an expanded corpus of press releases from January 2010 to May 2020 was used to increase the sample and better clustering

${ }_{4}$ Words that are often occur and do not reflect the meaning in the text

5 This approach does not consider the order of words in the text, and only the frequency of their occurrence is counted

6 A modification of the "bag of words" method - term frequency, the inverse of the document frequency (tf-idf): the more often a word appears in the press releases, the more likely it is important for a given text (tf, word frequency). If a word occurs in most of the corpus, then it becomes less significant for a separate text (idf, frequency in the document)
} 
for the corpus of press releases makes it possible to determine which of the topics is popular during a selected period of time, at which each word from the press release belongs with a certain probability ${ }^{7}$ to a hidden topic. The text of the Bank of Russia's press release is presented as a mixture of the given topics with the probability:

$$
\begin{gathered}
p(\theta, z, w \mid \alpha, \beta)= \\
=p(\theta \mid \alpha) \prod_{n=1}^{N} p\left(z_{n} \mid \theta\right) p\left(w_{n} \mid z_{n}, \beta\right),
\end{gathered}
$$

where $\theta-$ joint distribution of topics;

$w_{n}-n$-th word in the text;

$z_{n}$ - distribution of words in each topic;

$\alpha, \beta-$ hyperparameters characterizing the sparsity of topics in the document and the sparsity of the distribution of words in topics, respectively.

We evaluate LDA with 25 and 20 topics under vectorization "bag of words" and tf-idf for press releases of the Bank of the Russia, respectively.

The econometric analysis will only consider signals about the future direction of monetary policy. In case of topic modeling, the corresponding topics were obtained - Topic 7 (Figure 1) with vectorization "bag of words" and Topic 19 (Figure 2) with tf-idf vectorization. In Figures 1 and 2, can see the top 20 words from the distribution for the selected topics, which makes possible to identify topic of information signals of interest to us.

The future direction of the Bank of Russia's monetary policy in press releases is determined based on a dictionary of positive and negative words. For each of the filtered press releases, a measure of net optimism was calculated based on the dictionary as follows [28]:

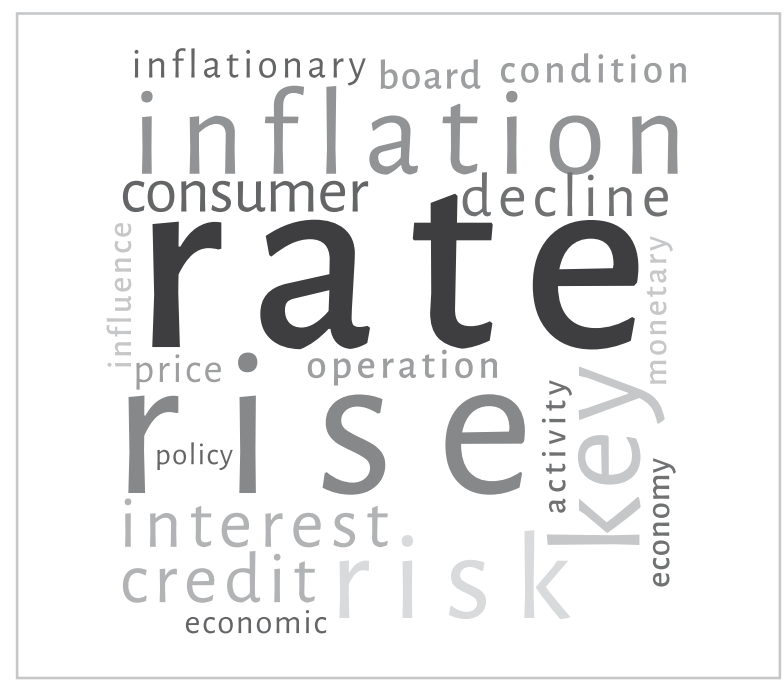

Fig. 1. Topic 7 "The Bank of Russia's signals about the future direction of monetary policy" in the LDA model with vectorization "bag of words"

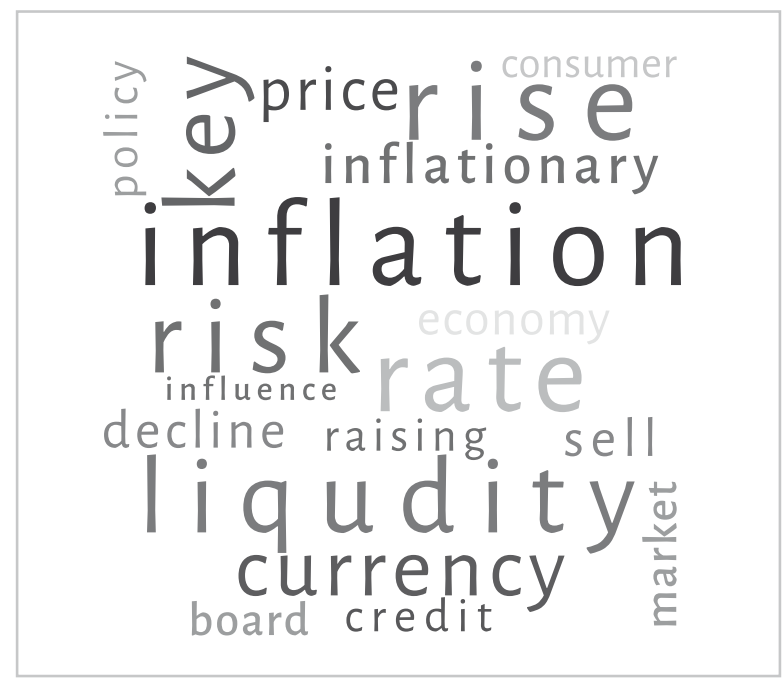

Fig. 2. Topic 19 "The Bank of Russia's signals about the future direction of monetary policy" in the LDA model with tf-idf

$$
S(A)=\frac{W_{p o s}(A)-W_{n e g}(A)}{W_{\text {tot }}(A)} \in[-1 ; 1]
$$

where $A$ - press release for which sentiment is calculated;

\footnotetext{
${ }^{7}$ In this case, we consider the probabilities of occurrence the j-th word in the text of a press release related to the $\mathrm{i}$-th topic

8 Press releases were selected that were related to this topic with a probability of at least $20 \%$
} 
$S(A)$-indicator of optimism built on the basis of analysis of press releases;

$W_{p o s}(A)-$ the number of words with a positive sentiment;

$W_{\text {neg }}(A)$ - the number of words with negative sentiment;

$W_{\text {tot }}(A)$ - total word count.

The resulting sentiment indicator should be interpreted in a certain way. If the values are positive, then the indicator assumes easing of monetary policy. On the contrary, if it is less than zero, then this indicates a tightening of monetary policy in the future.

The final indicators of information signals of the Bank of Russia were calculated as the multiplied the probability of attributing a press release to the relevant topic by the sentiment indicator:

$$
\begin{gathered}
\text { toptone }=\text { topic } 7 \cdot S\left(A_{t f i d f}\right) \\
\text { toptone_tfidf }=\text { topic } 19 \cdot S\left(A_{t f i d f}\right)
\end{gathered}
$$

where toptone and toptone_tfidf - information signals of the Bank of Russia with vectorization "bag of words" and tf-idf, respectively;

topic7 and topic7 - Topic 7 and Topic 19 of LDA models with vectorized "bag of words" and tf-idf, respectively;

$S\left(A_{b g}\right)$ and $S\left(A_{t f i d f}\right)-$ sentiment of press releases with vectorization "bag of words" and tf-idf, respectively.

\section{Econometric analysis \\ of the impact of Bank of Russia's signals on money market indicators}

In this paper we provide an econometric analysis of the impact of the Bank of Russia's signals about the future direction of monetary policy on various indicators of the money market using the exponential GARCH model. EGARCH makes it possible to simultaneously evaluate the impact of information signals on the conditional mean and conditional variance of money market indicators, as well as, to take into account the leverage effect ${ }^{9}$ and does not impose restrictions on the coefficients in the conditional variance equation in comparison with GARCH.

The model used two types of the Bank of Russia's information signals - "toptone" and "toptone_tfidf". The "toptone" are signals about future changes in monetary policy obtained from press releases in the latent Dirichlet allocation with vectorization "bag of words", and "toptone_tfidf" are signals about future changes in monetary policy obtained from press releases in the latent Dirichlet allocation with tf-idf vectorization. The signals indicators "toptone" and "toptone_tfidf" in the conditional mean equations should be interpreted as follows: if the indicators of information signals increase, monetary policy easing is expected, hence, the rates on the money market will decrease.

The model estimated by EGARCH $(1,1)$ is as follows:

$$
\begin{gathered}
y_{t}=c+\delta_{1} \text { signal }_{t-1}+\delta_{2} \text { dlogbrent }_{t}+X_{t}+\varepsilon_{t}, \\
\log \left(\sigma_{t}^{2}\right)=\omega+\alpha\left[\left|\frac{\varepsilon_{t-1}}{\sigma_{t-1}}\right|\right]+\beta \log \left(\sigma_{t-1}^{2}\right)+ \\
+\gamma \frac{\varepsilon_{t-1}}{\sigma_{t-1}}+\lambda_{1} \text { signal }_{t-1}+\lambda_{2} \text { dlogbrent }_{t},
\end{gathered}
$$

where $y_{t}-1$-day money market rate MIACR, term spread between 10-year and 2-year government bonds's rates, term spread between 10-year and 3-month government bonds's rates, credit spread between effective yield corporate bonds (CBONDS) and 10-year government bonds;

\footnotetext{
9 Volatility is characterized by an asymmetric reaction to good and bad news
} 
$c$ - constant in conditional mean equation;

signal - information signal of central bank: "toptone" ("bag of words") in specification 1 or "toptone_tfidf" (tf-idf) in specification 2;

$X_{t}$ - control variable, in particular, for the 1-day MIACR, the model included the logarithm of balances on correspondent accounts growth;

dlogbrent $t_{t}$ - oil price Brent growth (Resource: FINAM);

$$
\begin{aligned}
& \sigma_{t}^{2}-\text { conditional variance; } \\
& \varepsilon_{t}-\text { noise innovation. }
\end{aligned}
$$

The results of econometric analysis are shown in tables 1-4. For all indicators of the money market, a significant decrease in volatility was revealed with an increase in oil prices. This can be explained by the assumption that improvement in trade conditions increases the optimism of economic agents and reduces the uncertainty in the financial markets.

The expected results were obtained for MIACR. Easing of monetary policy expected in the future will be associated with a decrease in the one-day MIACR rate (Table 1) by 0.275 p.p. when vectorizing "bag of words" and by 0.16 p.p. when vectorizing tf-idf. The result is stable and significant for all information signals. The information on the expected monetary policy easing reduces the uncertainty in the money market, which is the reason for the decrease in the volatility of MIACR. The increase in liquidity on correspondent accounts was associated with a decrease in the MIACR by an average of 0.07 p.p.

The increase in oil prices is in line with the decrease in the MIACR by an average of 0.667 p.p., as the terms of trade are improving, inflation risks are decreasing and, possibly, monetary policy easing.
EGARCH $(1,1)$ estimation results

\begin{tabular}{|c|c|c|}
\hline Variable & Specification 1 & Specification 2 \\
\hline \multicolumn{3}{|c|}{ Conditional mean equation } \\
\hline dlogbrent $_{t}$ & $-0.668^{\star \star \star}$ & $-0.667^{\star \star \star}$ \\
\hline toptone $_{t-1}$ & $-0.275^{\star \star \star}$ & - \\
\hline toptone_tfidf $f_{t-1}$ & - & $-0.160^{\star \star \star}$ \\
\hline dlogcorr $_{t}$ & $-0.07^{\star \star \star}$ & $-0.067^{\star \star \star}$ \\
\hline \multicolumn{3}{|c|}{ Conditional variance equation } \\
\hline$\gamma$ & $0.032^{\star \star}$ & 0.032 \\
\hline toptone $_{t-1}$ & $-2.857^{\star \star \star}$ & - \\
\hline toptone_tfidf $f_{t-1}$ & - & $-2.324^{\star \star}$ \\
\hline dlogbrent $_{t}$ & $-6.759^{\star \star \star}$ & $-6.870^{\star \star}$ \\
\hline $\mathrm{LL}$ & 332.354 & 331.51 \\
\hline AIC & -0.354 & -0.353 \\
\hline SIC & -0.324 & -0.323 \\
\hline
\end{tabular}
for MIACR

Note: Significance levels ${ }^{* * *}-1 \%,{ }^{* *}-5 \%,{ }^{*}-10 \%$. Standard errors are shown in parentheses.

Results for the 10- and 2-year government bond yields spread and 10-year and 3-month government bond yields spread are presented in Tables 2 and 3. Higher oil prices also reduce term spreads. The signal of monetary policy easing precedes an increase in the term spread

\footnotetext{
${ }^{10}$ This allows for the model to take into account the impact of changes in liquidity in the banking sector
} 
Table 2.

EGARCH $(1,1)$ estimation results for 10 - and 2-year government bonds spread

\begin{tabular}{|c|c|c|}
\hline Variable & Specification 1 & Specification 2 \\
\hline \multicolumn{3}{|c|}{ Conditional mean equation } \\
\hline dlogbrent $_{t}$ & $-0.296^{\star \star \star}$ & $-0.294^{\star \star \star}$ \\
\hline toptone $_{t-1}$ & $0.086^{\star \star \star}$ & - \\
\hline toptone_tfidf $f_{t-1}$ & - & $0.062^{\star \star \star}$ \\
\hline \multicolumn{3}{|c|}{ Conditional variance equation } \\
\hline$\gamma$ & 0.013 & 0.013 \\
\hline toptone $_{t-1}$ & -0.458 & - \\
\hline toptone_tfidf & - & -0.380 \\
\hline dlogbrent $_{t}$ & $-2.760^{\star \star \star}$ & $-2.765^{\star \star \star}$ \\
\hline $\mathrm{LL}$ & 2505.54 & 2504.73 \\
\hline AIC & -2.745 & -2.744 \\
\hline SIC & -2.717 & -2.717 \\
\hline
\end{tabular}

Note: Significance levels ${ }^{\star * \star}-1 \%,{ }^{* \star}-5 \%,{ }^{*}-10 \%$. Standard errors are shown in parentheses.

of 10- and 2-year government bond yields by an average of 0.074 p.p., and the spread of 10-year and 3-month government bond yields by 0.059 p.p. with vectorization "bag of words".

In the literature, this is explained by the fact that interest rates decline more strongly with the expected easing of monetary policy in the short and medium term, compared with the long term. If the hypothesis of expectations
EGARCH $(1,1)$ estimation results for 10-year and 3-month government bonds spread

\begin{tabular}{c|c|c}
\hline Variable & Specification 1 & Specification 2 \\
\hline \multicolumn{3}{c}{ Conditional mean equation } \\
\hline dlogbrent $_{t}$ & $-0.429^{\star \star \star}$ & $-0.430^{\star \star \star}$ \\
\hline toptone $_{t-1}$ & $0.059^{\star \star \star}$ & - \\
\hline toptone_tfidf $_{t-1}$ & - & 0.022 \\
\hline
\end{tabular}

Conditional variance equation

\begin{tabular}{c|c|c}
\hline$\gamma$ & $0.148^{\star \star \star}$ & $0.147^{\star \star \star}$ \\
\hline toptone $_{t-1}$ & -0.343 & - \\
\hline toptone_tfidf $_{t-}$ & - & -1.086 \\
\hline dlogbrent $_{t}$ & $-3.734^{\star \star}$ & $-3.775^{\star \star \star}$ \\
\hline $\mathrm{LL}$ & 1377.405 & 1377.84 \\
\hline $\mathrm{AIC}$ & -1.505 & -1.505 \\
\hline SIC & -1.477 & -1.478 \\
\hline
\end{tabular}

Note: Significance levels ${ }^{\star * \star}-1 \%,{ }^{* \star}-5 \%,{ }^{*}-10 \%$. Standard errors are shown in parentheses.

regarding the term structure of interest rates is fulfilled and price rigidity is observed, then due to a larger decrease in rates in the short term, economic activity may increase.

An asymmetric response of volatility to positive and negative shocks was revealed for the term spread of 10-year and 3-month government bonds. Volatility rises more strongly with increasing term spread. 
As for the credit spread (the difference between the yields of corporate bonds and long-term 10-year government bonds), the easing of monetary policy corresponds to its decrease by an average of 0.065 p.p. (Table 4). This is due to the balance sheet channel of the transmission mechanism of monetary policy $^{11}$.

When the central bank reduces the interest rate, the net wealth of companies increases, while the external financial premium on corporate bonds decreases. Therefore, the yield on corporate bonds declines more than the long-term yield on government bonds, since along with a decrease in the key rate, there is a decrease in the default risk.

In general, the results show that information signals about the future changes in monetary policy contained in the press releases of the Bank of Russia are an important source of information when money market participants make decisions.

\section{Conclusion}

Since 2013, the communication policy of the Bank of Russia has become an important instrument of monetary policy. In this regard, in this article, we try to examine the degree of effectiveness of information signals of the Bank of Russia for the period 2013-2020. Text analysis of the Bank of Russia press releases was exercised to identify information signals. At the first stage, a topic modeling of the press release corpus was carried out to determine the importance of various economic issues at certain time intervals. At the second stage, a
GARCH $(1,1)$ estimation results for the yield spread of corporate and 10-year government bonds

\begin{tabular}{c|c|c}
\hline Variable & Specification 1 & Specification 2 \\
\hline \multicolumn{3}{c}{ Conditional mean equation } \\
\hline dlogbrent $t_{t}$ & $0.398^{\star \star \star}$ & $0.40^{\star \star \star}$ \\
\hline toptone $_{t-1}$ & $-0.056^{\star}$ & - \\
\hline toptone_tfidf $_{t-1}$ & - & $-0.073^{\star \star}$ \\
\hline \multicolumn{2}{c|}{ Conditional variance equation } \\
\hline$\gamma$ & -0.049 & -0.05 \\
\hline toptone $_{t-1}$ & -0.256 & - \\
\hline toptone_tfidf $_{t-}$ & - & -1.347 \\
\hline dlogbrent $t$ & $-4.707^{\star \star \star}$ & $-4.749^{\star \star \star}$ \\
\hline LL & 1639.891 & 1642.158 \\
\hline AlC & -1.793 & -1.796 \\
\hline SIC & -1.766 & -1.768 \\
\hline
\end{tabular}

Note: Significance levels *** $-1 \%,{ }^{*}-5 \%,{ }^{*}-10 \%$. Standard errors are shown in parentheses.

dictionary of positive and negative words was used to assess the directionality of information signals of monetary policy.

\footnotetext{
${ }^{11}$ The balance sheet channel shows how a change in the interest rate affects the welfare of economic agents through changes in the prices of financial assets that are part of net wealth and can be used as collateral for lenders. As such, the change in prices for financial assets affects the assessment of the default risk for economic agents

${ }^{12}$ External financial premium - the difference between the cost of raising finance through the sale of shares or bonds and the cost of using funds from the main economic activity
} 
Overall, the results indicate that information signals of the Bank of Russia play an important role in managing expectations by market participants, which has been illustrated for various indicators of the money market. The expected easing of monetary policy by the Bank of Russia was associated with a drop in the one-day
MIACR, a reduction of the term spread and an increase in the credit spread. Compared to international experience, which shows a decrease in uncertainty after monetary policy easing, the influence of information signals on the volatility of money market indicators was not revealed, with the exception of the MIACR.

\section{References}

1. Morris S., Shin H.S. (2002) Social value of public information. American Economic Review, vol. 92, no 5, pp. 1521-1534. DOI: 10.1257/000282802762024610.

2. Svensson L.E.O. (2006) Social value of public information: Comment: Morris and Shin (2002) is actually pro-transparency, not con. American Economic Review, vol. 96, no 1, pp. 448-452. DOI: $10.1257 / 000282806776157650$.

3. Angeletos G.M., Pavan A. (2004) Transparency of information and coordination in economies with investment complementarities. American Economic Review, vol. 94, no 2, pp. 91-98. DOI: 10.1257/0002828041301641.

4. Cornand C., Heinemann F. (2008) Optimal degree of public information dissemination. The Economic Journal, vol. 118, no 528, pp. 718-742. DOI: 10.1111/j.1468-0297.2008.02139.x.

5. Hellwig C. (2005) Heterogeneous information and the benefits of transparency. Available at: http://idei.fr/ sites/default/files/medias/doc/conf/jjl/papers/135hellwig.pdf (accessed 01 February 2021).

6. Rudebusch G.D., Williams J.C. (2008) Revealing the secrets of the temple: The value of publishing central bank interest rate projections. Asset Prices and Monetary Policy. Chicago: University of Chicago Press, pp. 247-289.

7. Faust J., Leeper E.M. (2005) Forecasts and inflation reports: An evaluation. Washington, DC: Federal Reserve Board.

8. Woodford M. (2005) Central bank communication and policy effectiveness. Working Paper 11898. Cambridge, MA: National Bureau of Economic Research. DOI: 10.3386/w11898.

9. Woodford M. (2001) Monetary policy in the information economy. Working Paper 8674. Cambridge, MA: National Bureau of Economic Research. DOI: 10.3386/w8674.

10. Mizen P. (2009) What can we learn from central bankers' words? Some nonparametric tests for the ECB. Economics Letters, vol. 103, no 1, pp. 29-32. DOI: 10.1016/j.econlet.2009.01.013.

11. Blinder A.S., Ehrmann M., Fratzscher M., De Haan J., Jansen D.J. (2008) Central bank communication and monetary policy: A survey of theory and evidence. Journal of Economic Literature, vol. 46, no 4, pp. 910-945. DOI: 10.1257/jel.46.4.910.

12. Guthrie G., Wright J. (2000) Open mouth operations. Journal of Monetary Economics, vol. 46, no 2 , pp. 489-516. DOI: 10.1016/S0304-3932(00)00035-0.

13. Hansen S., McMahon M., Tong M. (2019) The long-run information effect of central bank communication. Journal of Monetary Economics, vol. 108, pp. 185-202. DOI: 10.1016/j.jmoneco.2019.09.002.

14. Rosa C., Verga G. (2007) On the consistency and effectiveness of central bank communication: Evidence from the ECB. European Journal of Political Economy, vol. 23, no 1, pp. 146-175. DOI: 10.1016/j.ejpoleco.2006.09.016.

15. Ehrmann M., Fratzscher M. (2007) Communication by central bank committee members: different strategies, same effectiveness? Journal of Money, Credit and Banking, vol. 39, no 2-3, pp. 509-541. DOI: 10.1111/j.0022-2879.2007.00034.X.

16. Ehrmann M., Talmi J. (2020) Starting from a blank page? Semantic similarity in central bank communication and market volatility. Journal of Monetary Economics, vol. 111, pp. 48-62. DOI: 10.1016/j.jmoneco.2019.01.028.

17. Fišer R., Horvath R. (2010) Central bank communication and exchange rate volatility: a GARCH analysis. Macroeconomics and Finance in Emerging Market Economies, vol. 3, no 1, pp. 25-31. DOI: $10.1080 / 17520840903498099$.

18. Azar P.D., Lo A.W. (2016) The wisdom of Twitter crowds: Predicting stock market reactions to FOMC meetings via Twitter feeds. The Journal of Portfolio Management, vol. 42, no 5, pp. 123-134. DOI: 10.3905/jpm.2016.42.5.123. 
19. Hansen S., McMahon M. (2016) Shocking language: Understanding the macroeconomic effects of central bank communication. Journal of International Economics, vol. 99, suppl. 1, pp. S114-S133. DOI: 10.1016/j.jinteco.2015.12.008.

20. Moniz A., de Jong F. (2014) Predicting the impact of central bank communications on financial market investors' interest rate expectations. Proceedings of the European Semantic Web Conference (ESWC 2014). Anissaras, Crete, Greece, 25-29 May 2014, pp. 144-155. DOI: 10.1007/978-3-319-11955-7_12.

21. Correa R., Garud K., Londono J.M., Mislang N. (2021) Sentiment in central banks' financial stability reports. Review of Finance, vol. 25, no 1, pp. 85-120. DOI: 10.1093/rof/rfaa014.

22. Filatov D. (2020) Central banks communication and the state of the economy. Available at: https://papers. ssrn.com/sol3/papers.cfm?abstract_id=3519846 (accessed 01 February 2021). DOI: 10.2139/ssrn.3519846.

23. Hendry S. (2012) Central bank communication or the media's interpretation: What moves markets? Staff Working Papers. Bank of Canada, no 12-9.

24. Drobyshevsky S.M., Trunin P.V., Bozhechkova A.V., Gorunov E.V., Petrova D.V. (2017) Analysis of the Bank of Russia information policy. Voprosy Ekonomiki, no 10, pp. 88-110 (in Russian).

DOI: 10.32609/0042-8736-2017-10-88-110.

25. Kuznetsova O.S., Ulyanova S.R. (2018) The exchange rate and the verbal interventions by the government and the Bank of Russia. HSE Economic Journal, vol. 22, no 2, pp. 228-250 (in Russian). DOI: $10.17323 / 1813-8691-2018-22-2-228-250$.

26. Blei D.M., Ng A.Y., Jordan M.I. (2003) Latent Dirichlet allocation. The Journal of Machine Learning Research, no 3, pp. 993-1022.

27. Hoffman M., Bach F.R., Blei D.M. (2010) Online learning for latent Dirichlet allocation. Advances in Neural Information Processing Systems, no 23, pp. 856-864.

28. Förschler F., Alfano S. (2016) Reading between the lines: The effect of language sentiment on economic indicators. Proceedings of the 8th International Workshop on Enterprise Applications, Markets and Services in the Finance Industry (FinanceCom 2016). Frankfurt, Germany, 8 December 2016, pp. 89-104. DOI: 10.1007/978-3-319-52764-2_7.

\section{About the authors}

\section{Diana A. Petrova}

Research Fellow, Center for the Study of Problems of Central Banks, Institute of Applied Economic Research, Russian Presidential Academy of National Economy and Public Administration, 84, Prospect Vernadskogo, Moscow 119571, Russia;

E-mail: petrova-da@ranepa.ru

ORCID: 0000-0003-1030-4932

\section{Pavel V. Trunin}

Dr. Sci. (Econ.);

Director, Center for the Study of Problems of Central Banks, Institute of Applied Economic Research, Russian Presidential Academy of National Economy and Public Administration, 84, Prospect Vernadskogo, Moscow 119571, Russia;

Head of Macroeconomics and Finance Division, Gaidar Institute for Economic Policy, 3-5, Gazetnyy Lane, Moscow 125993, Russia

E-mail: pt@iep.ru

ORCID: 0000-0001-8306-9422 